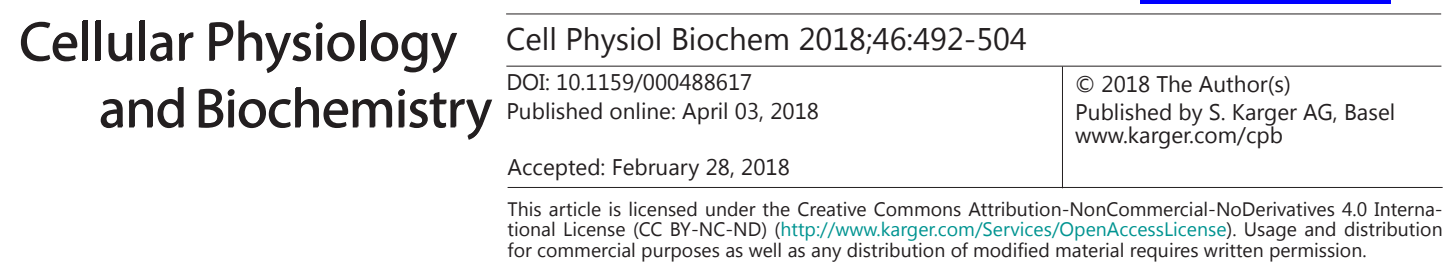

\title{
Propofol Disrupts Aerobic Glycolysis in Colorectal Cancer Cells via Inactivation of the NMDAR-CAMKII-ERK Pathway
}

\author{
Xiangyuan Chen ${ }^{a, b}$ Qichao Wua,b Pengfei Sun ${ }^{a, b}$ Yanjun Zhao ${ }^{a}$ Minmin Zhu \\ Changhong Miao
}

aDepartment of Anesthesiology, Fudan University Shanghai Cancer Center, Shanghai, b Department of Anesthesiology, Fudan University Shanghai Medical College, Shanghai, China

\section{Key Words \\ Propofol • Glycolysis • Colorectal cancer}

\begin{abstract}
Background/Aims: To investigate the effect of propofol on glucose metabolism in colorectal cancer cells and in an in vivo xenograft model. Methods: Glucose metabolism was assessed by measuring the extracellular acidification rate in HT29 and SW480 colorectal cancer cells. Quantitative real-time PCR and western blot analyses were used to detect mRNA and protein levels, respectively. Intracellular calcium was assessed by using a Fluo-3 AM fluorescence kit. Micro-positron emission tomography/computed tomography (microPET/CT) imaging was used to analyze glucose metabolism in the tumors of the xenograft model. Results: Propofol exposure induced a dose-dependent decrease of aerobic glycolysis in HT29 and SW480 colorectal cancer cells. MicroPET/CT indicated that propofol also inhibited ${ }^{18} \mathrm{~F}-\mathrm{FDG}$ uptake in the xenograft model. In addition, hypoxia-inducible factor $1 \alpha$ (HIF $1 \alpha)$ was also reduced by propofol dose-dependently. Propofol repressed the NMDAR-CAMKII-ERK pathway to inactivate HIF1 $\alpha$ and therefore reduced glycolysis. Conclusion: Propofol inhibited aerobic glycolysis in colorectal cancer cells through the inactivation of the NMDAR-CAMKII-ERK pathway, which may facilitate a better understanding of the use of propofol in the clinical setting.

(C) 2018 The Author(s)

Published by S. Karger AG, Basel
\end{abstract}

\section{Introduction}

Colorectal cancer is the most common cancer of the digestive system and the third most common cause of cancer-related death globally, accounting for approximately 1.3 million new cases and 50, 000 deaths per year [1]. With the introduction of sigmoidoscopy and colonoscopy, both the incidence and death rate of colorectal cancer declined in the USA and high-income countries. However, due to the adoption of dietary patterns and risk factors

X. Chen, Q. Wu and P. Sun contributed equally to this work.

Minmin Zhu

and Changhong Miao
Department of Anesthesiology, Fudan University Shanghai Cancer Center,

No.270 Dong'an Road, Shanghai (China)

Tel. 86-21-64175590, E-Mail zhu_mm@126.com, miao_chh@126.com

\section{KARGER}




\section{Cellular Physiology Cell Physiol Biochem 2018;46:492-504 \begin{tabular}{l|l} 
DOI: 10.1159/000488617 & $\begin{array}{l}\text { O } 2018 \text { The Author(s). Published by S. Karger AG, Basel } \\
\text { www.karger.com/cpb }\end{array}$
\end{tabular} \\ Chen et al.: Propofol Disrupts Aerobic Glycolysis in Colorectal Cancer Cells}

associated with a western lifestyle, its incidence has increased in previously low-risk countries, such as countries in Eastern Europe and East Asia [1-3].

Approximately $80 \%$ of patients are diagnosed with colorectal cancer at a local stage. Surgery is the standard protocol for the treatment of regional and liver metastasis tumors $[3,4]$. However, local recurrence and distant metastases remain serious issues after surgery [5]. Despite advances in neoadjuvant therapy, the 5-year relative survival rate for colorectal cancer remains at less than $50 \%$ in low-income countries. Epidemiological studies have consistently shown an interaction between the risk of colorectal cancer and various factors, such as inflammatory bowel disease [6], obesity [7], excessive alcohol consumption [8], and diabetes [9]. Although genome-wide association studies have identified multiple factors related to the progression of colorectal cancer, the molecular mechanisms underlying its development are still understood poorly.

Cancer cells reprogram their metabolic type to meet the demands of proliferating cells by shifting from oxidative phosphorylation to aerobic glycolysis, which is known as the Warburg effect [10]. The increased uptake of glucose and glycolytic rate as a result of this shift favor cancer cells by providing energy and intermediates for biosynthesis. The activation of hypoxia-inducible factor $1 \alpha$ (HIF $1 \alpha$ ) is one of the main mechanisms of aerobic glycolytic metabolism [11]. HIF1 $\alpha$ stimulates aerobic glycolysis by inducing the expression of glucose transporters (such as glucose transporter 1, GLUT1) and directly targeting enzymes that regulate glycolysis, such as hexokinase 2 (HK2), phosphoglycerate kinase 1 (PGK1), lactate dehydrogenase A (LDHA), monocarboxylate transporter 4, and pyruvate dehydrogenase lipoamide kinase isozyme 1 (PDK1) [12]. A number of studies have revealed the importance of this metabolic reprogramming in cancer cells [13-17].

Surgery for malignant cancers aims at eliminating cancer cells; however, it may also promote the distant spread of tumor cells, leading to metastases [18]. Recent discoveries have suggested that anesthesia could induce metabolic, inflammatory, and immunological changes in the perioperative period [19]. Propofol (2, 6-diisopropylphenyl) is a widely used agent during the induction and maintenance of anesthesia. It has been revealed recently that propofol exerts antitumor effects against some malignancies via inhibition of cell viability and the dispersion and invasion capacity of cancer cells [20-22]. However, its effect on glucose metabolism in cancer cells is not well understood. Therefore, in this study we investigated the effect of propofol on glucose metabolism using HT29 and SW480 colorectal cancer cells, and explored the potential mechanism by which propofol suppresses aerobic glycolysis.

\section{Materials and Methods}

\section{Cell culture and regents}

Human HT29 (ATCC ${ }^{\circledR} \mathrm{HTB}-38^{\mathrm{TM}}$ ) and SW480 (ATCC ${ }^{\circledR}$ CCL-228 ${ }^{\mathrm{TM}}$ ) colorectal cancer cells, murine CT26 colon cancer cell lines (ATCC ${ }^{\circledR}$ CRL-2368 ${ }^{\mathrm{TM}}$ ), human colon mucosal epithelial NCM460 cells, and human umbilical vascular endothelial cells (HUVECs) were purchased from the American Type Culture Collection. HT29, SW480, and CT26 cell lines were cultured in Dulbecco's modified Eagle's medium (DMEM; Hyclone, Australia); the NCM460 cell line was cultured in RPMI 1640 medium (Hyclone, Australia); and HUVECs were cultured in DMEM (5 mM glucose). All culture media were supplemented with $10 \%$ fetal bovine serum (Gibco, Australia), $100 \mathrm{U} / \mathrm{mL}$ penicillin, and $100 \mathrm{mg} / \mathrm{mL}$ streptomycin, with the cells maintained in a humidified $5 \% \mathrm{CO}_{2}$ atmosphere at $37^{\circ} \mathrm{C}$. Cell medium was changed every day, and the cells were passaged until they reached $80-90 \%$ confluence. Cells at passages 4-10 were used in this study.

Propofol (Sigma-Aldrich, St. Louis, MO, USA) was dissolved in dimethyl sulfoxide (DMSO; SigmaAldrich). KN93, an inhibitor of calcium/calmodulin-dependent protein kinase II (CAMKII), and dizocilpine, also known as MK801, an uncompetitive antagonist of the N-methyl-D-aspartate receptor (NMDAR), were purchased from Selleck (Shanghai, China). Rapastinel, a selective, partial agonist of NMDARs, was purchased from Sigma-Aldrich. KN93, MK801, and rapastinel were dissolved in DMSO, respectively. 


\section{Cellular Physiology Cell Physiol Biochem 2018;46:492-504 \begin{tabular}{l|l} 
and Biochemistry Published online: April 03, 2018 & $\begin{array}{l}\text { (c) } 2018 \text { The Author(s). Published by S. Karger AG, Basel } \\
\text { www.karger.com/cpb }\end{array}$ \\
\hline
\end{tabular} \\ Chen et al.: Propofol Disrupts Aerobic Glycolysis in Colorectal Cancer Cells}

\section{Computational analysis of The Cancer Genome Atlas (TCGA) RNASeqV2 data}

Colorectal cancer RNASeqV2 data and clinical data were downloaded using TCGA Assembler [23]. Patients were classified into low or high gene expression groups using median expression calculated by Cox regression analysis. Survival differences between each group were assessed by Kaplan-Meier methods and compared using the log-rank test. All statistical tests were two-sided and performed with SPSS software.

\section{Propofol exposure}

During the induction and maintenance of anesthesia, the plasma concentration of propofol ranges from 5 to $50 \mu \mathrm{M}$ [24]. In this study, propofol was administered to the cells in a concentration gradient (5, $25,50$, and $100 \mu \mathrm{M})$ for $4 \mathrm{~h}$. DMSO $(<0.1 \%)$ was administered to the cells as a control group in extracellular acidification rate (ECAR) analysis. The concentration of propofol that had a significant inhibitory effect on glucose metabolism was determined in the ECAR assay, and then used in the following experiments. Since DMSO had no effect on ECAR compared with the blank control group, this group was not included in the following experiments. KN93 $(10 \mu \mathrm{M})$ and MK801 $(500 \mu \mathrm{M})$ were administered to the indicated groups, respectively. Propofol $(50 \mu \mathrm{M})$ and rapastinel $(50 \mu \mathrm{M})$ were administered to the cells simultaneously.

\section{Western blotting}

Briefly, the cells were collected and solubilized with RIPA lysis buffer (Beyotime Biotechnology, Suzhou, China) supplemented with protease and phosphatase inhibitors (Roche, Rotkreuz, Switzerland). The lysates were mixed with $5 \times$ loading buffer and boiled for $5 \mathrm{~min}$ at $100^{\circ} \mathrm{C}$. The proteins were resolved in a $10 \%$ SDS-polyacrylamide gel and transferred to a polyvinylidene fluoride membrane (Millipore, Billerica, MA) using a semidry electroblotting system. Then, the membranes were blocked with 5\% skim milk in phosphate-buffered saline-Tween 20 (PBST) for $1 \mathrm{~h}$ at room temperature, followed by incubation with a 1:1, 000 dilution of the primary antibody at $4^{\circ} \mathrm{C}$ overnight. The membranes were then washed with PBST and incubated with a 1:5, 000 dilution of goat anti-rabbit IgG $(\mathrm{H}+\mathrm{L})$, HRP conjugate (Proteintech, Wuhan, China) for $1 \mathrm{~h}$ at room temperature. After washing, the signals were detected using a LAS- 4000 mini CCD camera (GE Healthcare).

\section{Total RNA extraction}

Total RNA was extracted using TRNzol (Tiangen, Beijing, China). Chloroform was added and the lysates were centrifuged at $12,000 \times g$ for $15 \mathrm{~min}$ at $4^{\circ} \mathrm{C}$. The supernatant was transferred to a new centrifuge tube. RNA was precipitated with $100 \%$ ethanol. The samples were rinsed with $75 \%$ DEPC-alcohol. Each RNA sample was diluted in $30 \mu \mathrm{L}$ RNase-free water. The quantity and quality of RNA were assessed using a NanoDrop 2000c Spectrophotometer (Thermo Fisher, USA).

\section{cDNA preparation and quantitative real-time PCR ( $q R T-P C R)$}

cDNA was synthesized by reverse transcription using a TaKaRa PrimeScript ${ }^{\circledR}$ RT Reagent Kit with gDNA eraser. Briefly, a mixture containing $1 \mu \mathrm{g}$ RNA, $2.0 \mu \mathrm{L} 5 \times$ gDNA eraser buffer, and RNase-free water up to 10 $\mu \mathrm{L}$ was incubated at $42^{\circ} \mathrm{C}$ for $2 \mathrm{~min}$. Then, $4.0 \mu \mathrm{L}$ of $5 \times$ PrimeScript $^{\circledR}$ Buffer2, $1.0 \mu \mathrm{L}$ PrimeScript ${ }^{\circledR} \mathrm{RT}$ Enzyme Mix I, $1.0 \mu \mathrm{L}$ RT Primer Mix, and RNase-free water up to $20 \mu \mathrm{L}$ were added to the mixture. The RT reaction mixture had a final volume of $20 \mu \mathrm{L}$ and was incubated at $42^{\circ} \mathrm{C}$ for $15 \mathrm{~min}$ and $85^{\circ} \mathrm{C}$ for $5 \mathrm{~s}$. The expression of candidate genes and $\beta$-actin was determined by qRT-PCR. The PCR was run using a QuantStudio 7 Flex RealTime PCR System (Applied Biosystems) starting with denaturation at $95^{\circ} \mathrm{C}$ for $30 \mathrm{~s}$ followed by 40 cycles of $95^{\circ} \mathrm{C}$ for 5 $\mathrm{s}, 60^{\circ} \mathrm{C}$ for $30 \mathrm{~s}$ (annealing), a terminal extension step at $95^{\circ} \mathrm{C}$ for $10 \mathrm{~s}$, and a final holding stage at $4^{\circ} \mathrm{C}$. Melt curve controls were run to ensure primer specificity. All of the reactions were run in triplicate. The primer sequences used are listed in Table 1.

Table 1. Primers of genes in glycolysis

\begin{tabular}{lcc}
\hline Genes & \multicolumn{2}{c}{ Forward } \\
& & Reverse \\
\hline GLUT & 5'-TTGTTGTAGAGCGAGCTGGACGAC-3' & 5'-GGCCACGATGCTCAGATAGGACA-3' \\
1 & & \\
HK-2 & 5'-CCTTGCTGAAGGAAGCCATTCGC-3' & 5'-ACGCATCTCCTCCATGTAGCAGG-3' \\
PGK1 & 5'-GGATGAGGTGGTGAAAGCCACTTC-3' & 5'-CATTGCTGAGAGCATCCACCCCA-3' \\
LDHA & 5'-ACATGGCGACTCCAGTGTGCCTGT-3' & 5'-GAGGCCAATGGCCCAGGATGTGTA-3' \\
Actin & 5'-ATGCCCTGAGGCTCTTTTCCAGCC-3' & 5'-CCAGGATGGAGCCACCGATCCACA-3' \\
\hline
\end{tabular}




\section{Cellular Physiology Cell Physiol Biochem 2018;46:492-504 and Biochemistry Published online: April 03, $2018 \quad \begin{aligned} & \text { DOI 10159/00048618 The Author(s). Published by S. Karger AG, Basel } \\ & \text { www.karger.com/cpb }\end{aligned}$ \\ Chen et al.: Propofol Disrupts Aerobic Glycolysis in Colorectal Cancer Cells}

ECAR

Mitochondrial function was measured using a Seahorse Bioscience XF96 Extracellular Flux Analyzer according to the manufacturer's instructions. Briefly, the cells were seeded at a density of $2.0 \times 10^{4}$ cells per well in a 96-well cell culture XF microplate for $24 \mathrm{~h}$ prior to assay. The cells were switched to Seahorse buffer (DMEM with phenol red containing $25 \mathrm{mmol} / \mathrm{L}$ glucose, $2 \mathrm{mmol} / \mathrm{L}$ sodium pyruvate, and $2 \mathrm{mmol} / \mathrm{L}$ glutamine) at $1 \mathrm{~h}$ prior to assay. Then, $25 \mu \mathrm{L}$ each of $10 \mathrm{mmol} / \mathrm{L}$ glucose, $1 \mu \mathrm{mol} / \mathrm{L}$ oligomycin, and 100 mmol/L 2-deoxy-glucose were added to measure the ECAR. Each measurement cycle consisted of a mixing time of $3 \mathrm{~min}$ and a data acquisition period of $3 \mathrm{~min}$ for the XF96. Glucose stimulation indicates the cell glycolysis rate and oligomycin inhibition indicates the cell glycolysis capacity. ECAR levels were calculated after normalization to cell number and are plotted as mean \pm standard deviation (SD).

\section{Detection of intracellular $\mathrm{Ca}^{2+}$}

Intracellular $\mathrm{Ca}^{2+}$ measurements were performed using a Fluo-3 AM Fluorescence Kit (Beyotime, China). The cells were seeded at a density of $2.0 \times 10^{6}$ cells per well in a 6-well plate. After treatment, the cells were washed with PBS prior to the addition of the Fluo-3 AM fluorescence probes $(0.5 \mu \mathrm{M})$ to each well. The cells were then incubated with the probes for $60 \mathrm{~min}$ at $37^{\circ} \mathrm{C}$ protected from light. After incubation, the cells were washed with serum-free medium 3 times to remove extracellular Fluo-3 AM that might have entered the cells. The intensity of Fluo-3 AM was assessed using flow cytometry at $488 \mathrm{~nm}$ according to the manufacturer's instructions. Intracellular $\mathrm{Ca}^{2+}$ concentration was proportional to fluorescence intensity. Each assay was performed in three replicates, and the levels of intracellular $\mathrm{Ca}^{2+}$ are presented as mean $\pm \mathrm{SD}$.

\section{Animal treatment}

BALB/c mice (female, 4-6 weeks of age, 18-20 g; Shanghai SLAC Laboratory Animal Co., Ltd.) were housed under pathogen-free conditions and given food and acidified water ad libitum. Twenty-five mice were divided randomly into 5 groups. CT26 cells were treated with propofol (50 $\mu \mathrm{M}), \mathrm{KN} 93(10 \mu \mathrm{M})$, MK801 $(500 \mu \mathrm{M})$, propofol $(50 \mu \mathrm{M})$ with rapastinel $(50 \mu \mathrm{M})$, or DMEM, as a control group, for $4 \mathrm{~h}$. The mice of each group were injected subcutaneously with $2.0 \times 10^{5}$ CT26 cells in $100 \mu \mathrm{L}$ PBS. At 2 weeks after tumor implantation, the mice were subjected to micro-positron emission tomography/computed tomography (microPET/CT) before they were euthanized, and the tumors were then dissected, photographed, and subjected to qRT-PCR and western blot analyses. Data are presented as the mean \pm standard error (SE) or SD. All animal experiments were performed according to the Guidelines for the Care and Use of Laboratory Animals and were approved by the Institutional Animal Care and Use Committee of Fudan University.

\section{MicroPET/CT imaging}

MicroPET/CT imaging was performed according to the manufacturer's instructions. Briefly, ${ }^{18} \mathrm{~F}-\mathrm{FDG}$ was produced in a cyclotron (Siemens CTI RDS Eclipse ST) using an Explora FDG4 module. Each mouse was injected with $11.1 \mathrm{MBq}(300 \mu \mathrm{Ci})$ of ${ }^{18} \mathrm{~F}-\mathrm{FDG}$ through the tail vein. Scanning started at $1 \mathrm{~h}$ after injection. Images were reconstructed using a three-dimensional ordered-subset expectation maximization/maximum algorithm. An Inveon ${ }^{\mathrm{TM}}$ Research Workplace was used to obtain the percentage injected dose per gram (\%ID/g) and standardized uptake values (SUVs). SUVmax was calculated.

\section{Statistical analysis}

Data were obtained from at least 5 independent experiments and expressed as the mean \pm SD. Groups were compared using one-way analysis of variance followed by pairwise comparisons between groups with Dunnett's t test. On the basis of our previous experiments, we set $\alpha$ at 0.05 , power at 0.8 , to achieve a moderate effect size $(0.5=$ moderate $[1 / 2$ of an SD]), and a minimum sample size of 5 mice in each group. Overall survival and disease-free survival curves were calculated according to the Kaplan-Meier method, and comparisons were performed using the log-rank test. Univariate and multivariate Cox regression analyses were conducted to explore the independent predictors of prognosis. SPSS and GraphPad Prism software version 6.0 (GraphPad Software, Inc., La Jolla, CA, USA) were used for statistical analyses, and differences were considered significant at $\mathrm{P}<0.05$. 


\section{Results}

\section{Propofol inhibits aerobic glycolysis in colorectal cancer cells}

Cancer cells reprogram their metabolic pathway to glycolysis (Fig. 1A). First, we examined glucose uptake and lactate production by performing ECAR analysis. HT29 and SW480 cells were exposed to different concentrations of propofol $(5,25,50$, and $100 \mu \mathrm{M})$ for 4 h. As shown in Fig. 1B, propofol decreased glycolytic capacity in a dose-dependent manner. This decrease was significant at concentrations of 50 and $100 \mu \mathrm{M}$ propofol. Therefore, we chose $50 \mu \mathrm{M}$ for the following experiments. Moreover, no significant effect was observed

Fig. 1. Propofol (PPF) inhibits aerobic glycolysis in HT29 and SW480 colorectal cancer cells. A. Schematic representation of aerobic glycolysis in cancer cells. B. ECAR, an indicator of glycolysis, was reduced by propofol in a dosedependent manner. ECAR bar values represent glycolytic capacity. mRNA (C) and protein (D) expression of glucose transporter and enzymes involved in glycolysis (GLUT1, HK2, PGK1, and LDHA) was decreased by propofol in a dose-dependent manner. The cells were incubated with different concentrations of propofol $(5,25,50$, and $100 \mu \mathrm{M})$ or control DMSO $(<0.1 \%)$ for $4 \mathrm{~h}$. Error bars indicate mean \pm SD $(n=5)$. Effect of propofol (PPF) on normal colon NCM460 cells and HUVECs. Propofol had little effect on the ECAR of NCM460 cells and HUVECs (E). mRNA (F) and protein (G) levels of glucose transporter and glycolytic enzymes in NCM460 cells and HUVECs were not affected by propofol. Error bars indicate mean \pm SD $(n=5)$. NS, not significant. ${ }^{*} \mathrm{P}<0.05$, ${ }^{* *} \mathrm{P}<0.01$, compared with the

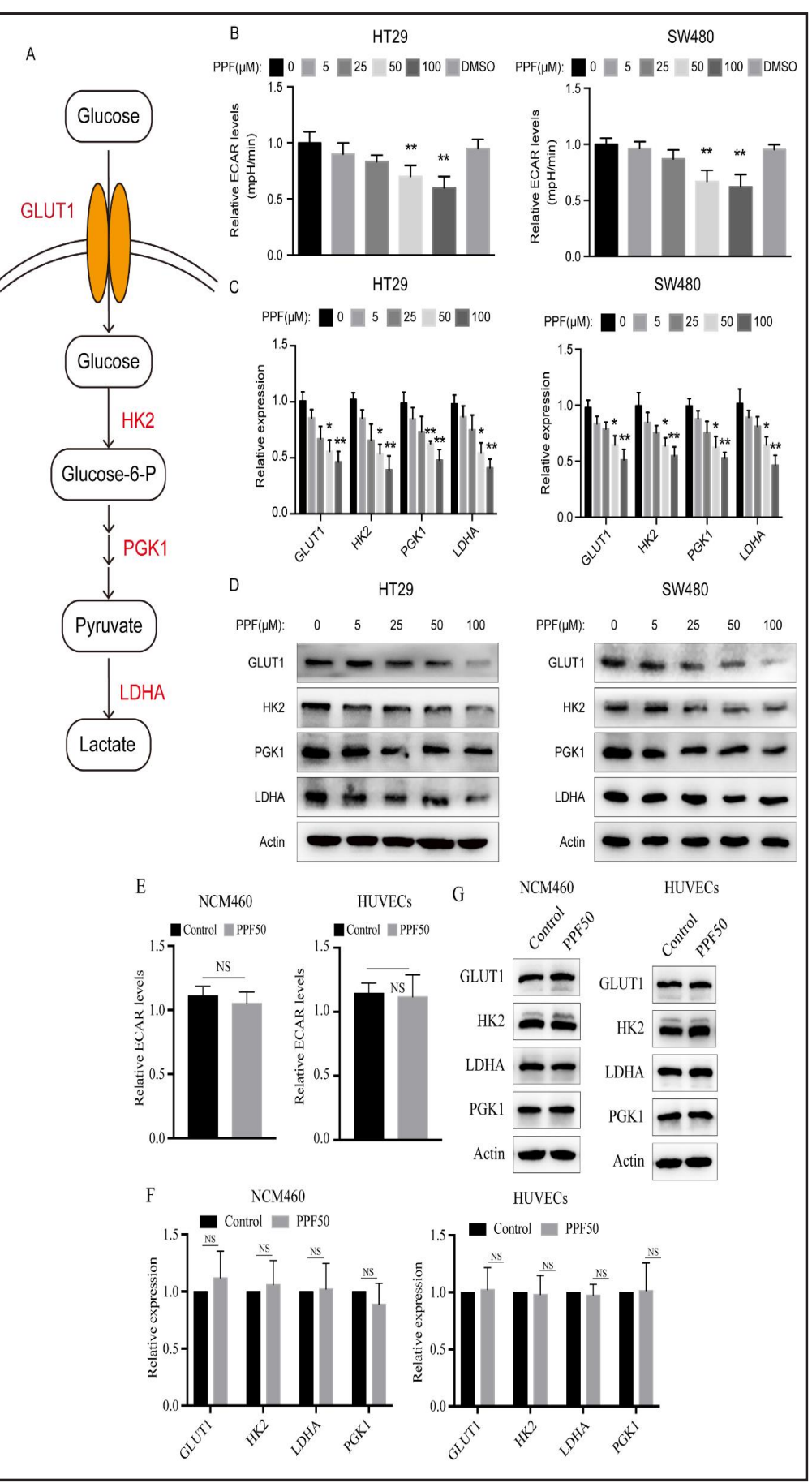




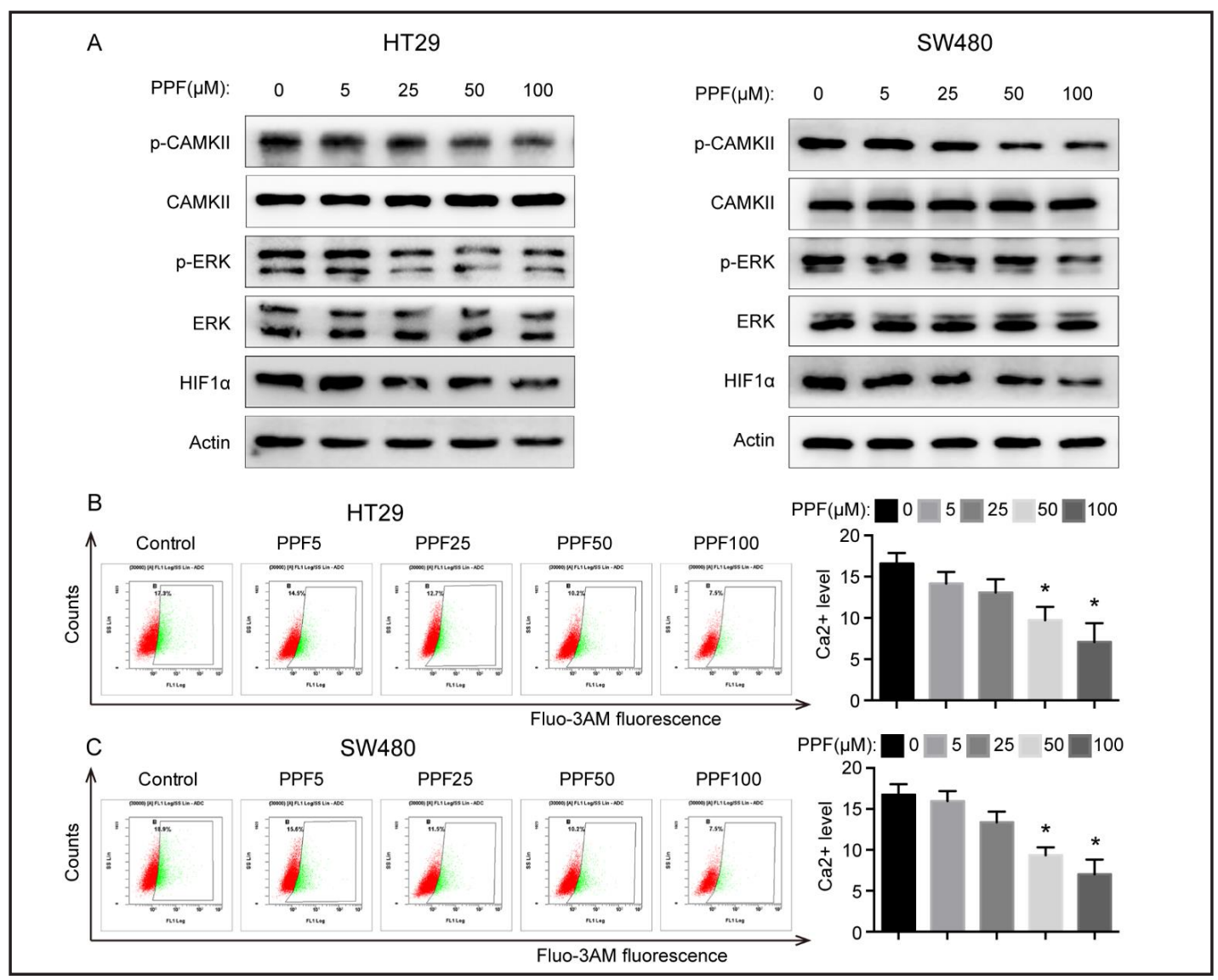

Fig. 2. Propofol (PPF) attenuates the levels of p-CAMKII, p-ERK, and HIF1 $\alpha$ in HT29 and SW480 colorectal cancer cells in a dose-dependent manner (A), while total CAMKII and ERK were not decreased. Intracellular $\mathrm{Ca}^{2+}$ concentration was reduced in cells exposed to propofol $(\mathrm{B}, \mathrm{C})$. The cells were incubated with different concentrations of propofol $(5,25,50$, and $100 \mu \mathrm{M})$ for $4 \mathrm{~h}$. Error bars indicate mean $\pm \mathrm{SD}(\mathrm{n}=5) .{ }^{*} \mathrm{P}<0.05$, compared with the control group.

in DMSO-treated cells. To assess further the role of propofol in glucose metabolism, key enzymes of the glycolysis cascade were examined. Enzymes related to glycolysis, such as GLUT1, HK2, PGK1, and LDHA, were decreased both at the mRNA and protein levels (Fig. 1C and 1D). To validate the specific inhibitory role of propofol on cancer cells, we examined its effect on NCM460 and HUVECs. Fig. 1E, $1 \mathrm{~F}$ and $1 \mathrm{G}$ showed that propofol had little inhibitory effect on the glucose metabolism of normal cells.

\section{Propofol suppresses HIF1 $\alpha$ expression}

Activation of the HIF1 $\alpha$ transcription factor drives the metabolic changes necessary to increase glycolysis in tumor cells [12]. By recognizing hypoxia-responsive elements in the promoters of target genes, HIF1 $\alpha$ directly regulates the enzymes necessary for glycolysis. Therefore, we investigated the expression of HIF1 $\alpha$ in HT29 and SW480 cells following exposure to different concentrations of propofol $(5,25,50$, and $100 \mu \mathrm{M})$ for $4 \mathrm{~h}$. Propofol reduced HIF1 $\alpha$ expression in a dose-dependent manner (Fig. 2A).

\section{Propofol reduces intracellular $\mathrm{Ca}^{2+}$ concentration and CAMKII phosphorylation}

In the central nervous system, CAMKII is best known for its role in learning and memory through $\mathrm{Ca}^{2+}$ signaling. However, recent studies have established critical roles for CAMKII in cancer progression. In cancer cells, remodeling of $\mathrm{Ca}^{2+}$ signaling helps to sustain most of the hallmarks of cancer. We next examined the effect of propofol on intracellular $\mathrm{Ca}^{2+}$

\section{KARGER}


Fig. 3. KN93 and MK801 mimic the effect of propofol (PPF) in glycolysis, while rapastinel reverses the effect of propofol. The cells were incubated with propofol $(50 \mu \mathrm{M})$, KN93 $(10 \mu \mathrm{M})$, MK801 (500 $\mu \mathrm{M})$, or propofol $(50 \mu \mathrm{M})$ with rapastinel $(30 \mu \mathrm{M})$ for $4 \mathrm{~h}$. KN93 and MK801 induced the same effect as propofol for inhibiting the ECAR (A) and the mRNA (B) and protein (C) expression of GLUT1, HK2, PGK1, and LDHA. ECAR bar values represent glycolytic capacity. Error bars indicate mean \pm SD (n = 5). ${ }^{*} \mathrm{P}<0.05$, ${ }^{* *} \mathrm{P}<0.01$, compared with the control group; $\# \mathrm{P}<0.05$, compared with the propofol group.

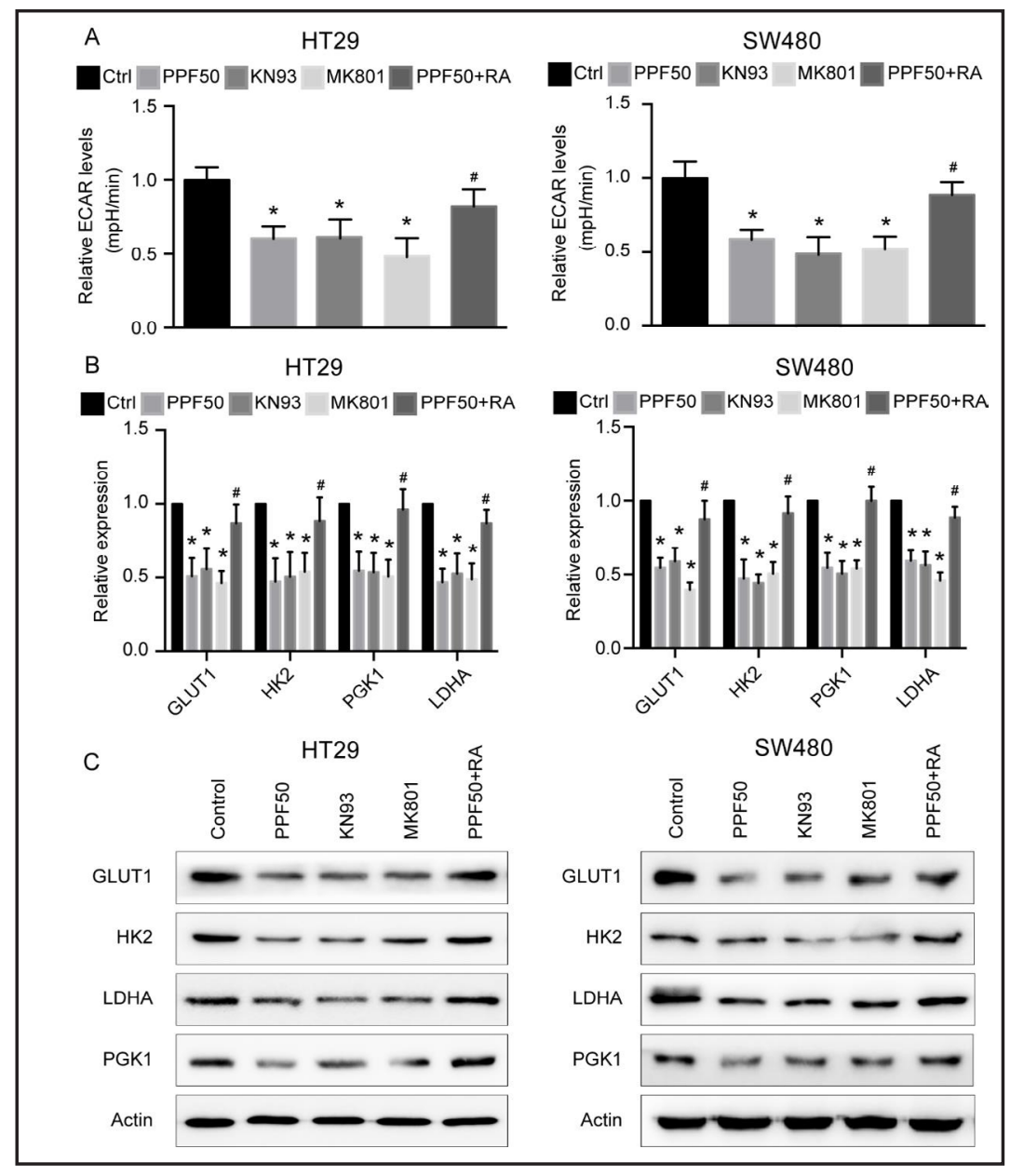

Fig. 4. NMDAR-CAMKII-ERKHIF1 $\alpha$ signaling in propofol (PPF)-induced glycolysis inhibition. MK801 reduced intracellular $\mathrm{Ca}^{2+}$ concentration, as propofol did (A). KN93 had no effect on intracellular $\mathrm{Ca}^{2+}$ concentration (A). MK801 and KN93 inhibited the levels of p-CAMKII, p-ERK, and HIF1 $\alpha$, while total CAMKII and ERK were not changed (B). Rapastinel reversed the effect of propofol (A, B). The cells were incubated with propofol $(50 \mu \mathrm{M})$, KN93 $(10 \mu \mathrm{M})$, MK801 (500 $\mu \mathrm{M})$, or propofol $(50 \mu \mathrm{M})$ with rapastinel $(30 \mu \mathrm{M})$ for $4 \mathrm{~h}$. Error bars indicate mean $\pm \mathrm{SD}(\mathrm{n}=$ 5). ${ }^{*} \mathrm{P}<0.05$, compared with the control group; $\# \mathrm{P}<0.05$, compared with the propofol group.

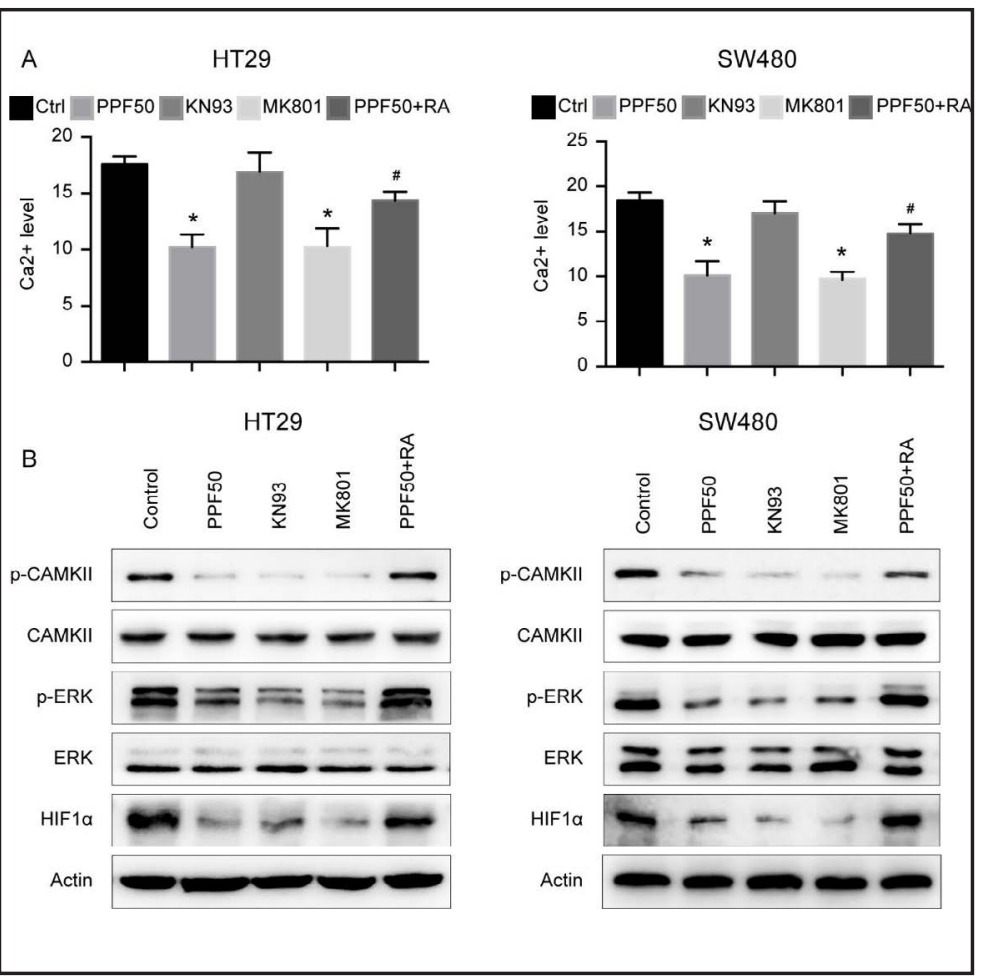


Fig. 5. Propofol (PPF) inhibits glycolysis and tumor growth in vivo. Propofol, KN93, and MK801 inhibited tumor growth in vivo, while rapastinel reversed the effect of propofol (A). MicroPET/ CT indicated that propofol, KN93, and MK801 suppressed glucose metabolism in tumors and tumor SUV ${ }_{\text {max }}$ while rapastinel reversed the effect of propofol $(B, C)$. qRT-PCR and immunoblot analyses of tumor issues showed that the mRNA and protein expres-

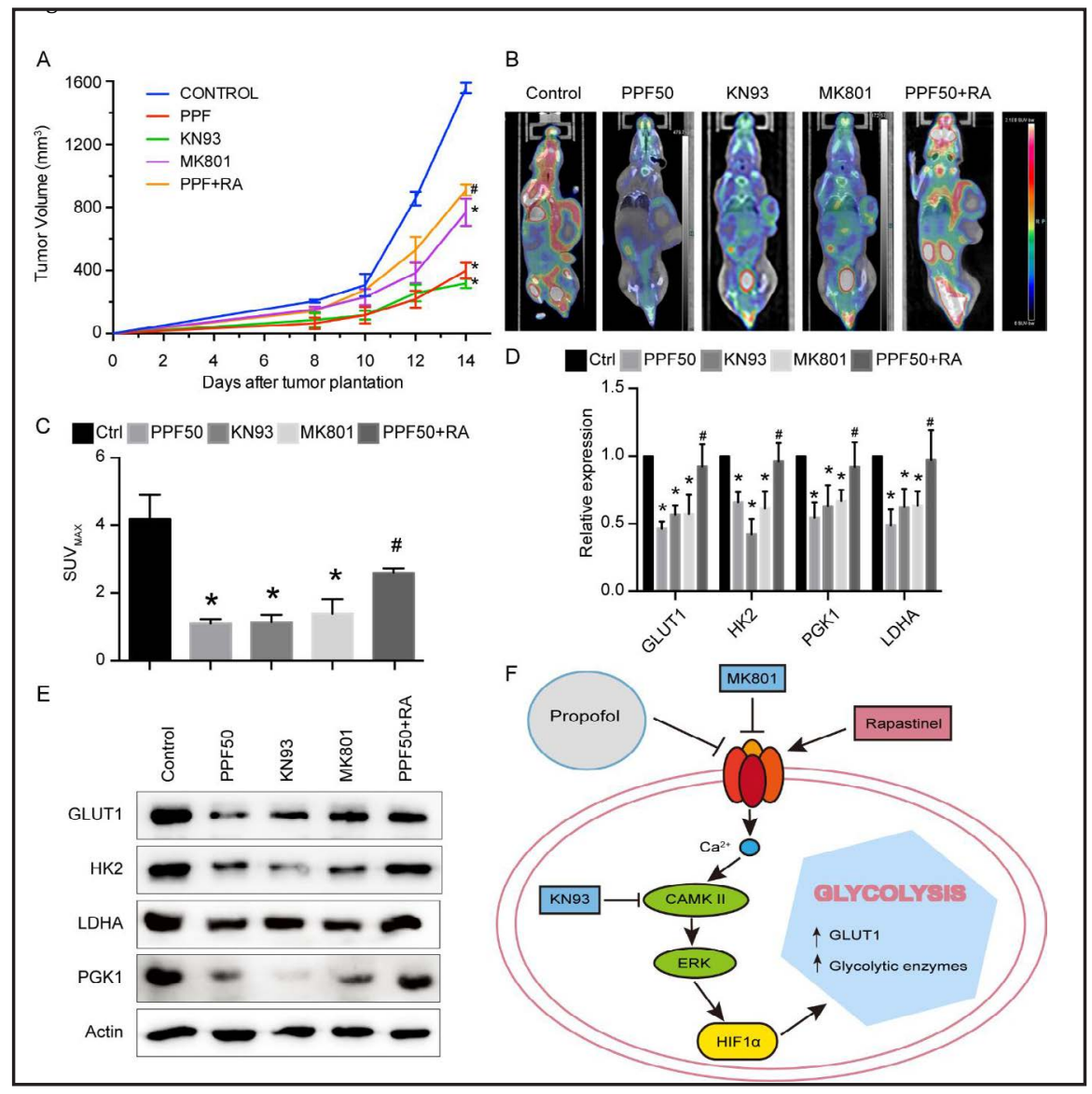
sion of the glyco-

lytic enzymes GLUT1, HK2, PGK1, and LDHA was decreased in tissues from the propofol, KN93, and MK801 groups, while it was increased in the rapastinel+propofol group, compared with the propofol group (D, E). The cells were incubated with propofol $(50 \mu \mathrm{M})$, KN93 $(10 \mu \mathrm{M})$, MK801 $(500 \mu \mathrm{M})$, or propofol $(50 \mu \mathrm{M})$ with rapastinel $(50 \mu \mathrm{M})$ for $4 \mathrm{~h}$. Then, the cells with different treatments were injected subcutaneously to different groups of mice. Tumor volume was measured with Vernier calipers every other day, and calculated as a (length) $\times \mathrm{b}^{2}$ (width). The mice were subjected to microPET/CT before the tumors were removed. Error bars indicate mean $\pm \mathrm{SE}(\mathrm{A}) / \mathrm{SD}(\mathrm{n}=5) .{ }^{*} \mathrm{P}<0.05$, compared with the control group; $\# \mathrm{P}<0.05$, compared with the propofol group. (F) Schematic overview of the signaling pathway in propofol-inhibited glycolysis. Propofol inactivated NMDAR, and thus inhibited the CAMKII-ERK-HIF1 $\alpha$ signaling pathway, leading to glycolytic inhibition. MK801, an antagonist of NMDAR, and KN93, an antagonist of CAMKII, mimicked the inhibitory effect of propofol, while rapastinel, an agonist of NMDAR, reversed the inhibitory effect of propofol.

concentration and CAMKII phosphorylation. Treatment with a concentration gradient of propofol resulted in a dose-dependent decrease in intracellular $\mathrm{Ca}^{2+}$ concentration (Fig. 2B and 2C) and CAMKII phosphorylation (Fig. 2A). However, the total expression of CAMKII was not altered.

CAMKII activation reportedly leads to extracellular signal-regulated kinase (ERK) activation and cell proliferation, and ERK activation is essential for HIF1 $\alpha$ activation [25]. Thus, we determined the level of phosphorylated (p)-ERK after exposure to propofol. As shown in Fig. 2A, ERK1/2 phosphorylation was decreased in propofol-treated cells in a dosedependent manner.

Propofol represses aerobic glycolysis by inhibiting NMDAR

Previous studies have shown that propofol inhibits NMDAR, which maintains $\mathrm{Ca}^{2+}$ flux and was recently found to be involved in cancer progression. Therefore, we hypothesized 
that NMDAR signaling is a key mechanism in propofolinduced glycolysis inhibition. To elucidate the NMDARCAMKII-ERK-HIF1 $\alpha$ signaling pathway, MK801 (500 $\mu \mathrm{M})$, an NMDAR antagonist, and KN93 $(10 \mu \mathrm{M})$, a CAMKII antagonist, were administered to cells separately to mimic the effect of propofol. Compared with the control group, MK801 and KN93 induced a significant decrease in glycolytic capacity (Fig. 3A), and the mRNA and protein levels of glycolytic enzymes were also reduced, which was consistent with the effect of propofol (Fig. 3B and 3C).

To assess further the role of NMDAR in propofol-induced glucose metabolism inhibition, we used an agonist of NMDAR, rapastinel, and evaluated the co-effect of rapastinel and propofol on glucose metabolism. Rapastinel (50 $\mu \mathrm{M})$ was administered to the cells together with propofol. We observed that NMDAR activation reversed the effect of propofolonglycolytic inhibition (Fig. 3A). Furthermore, the protein and mRNA levels of enzymes involved in glycolysis

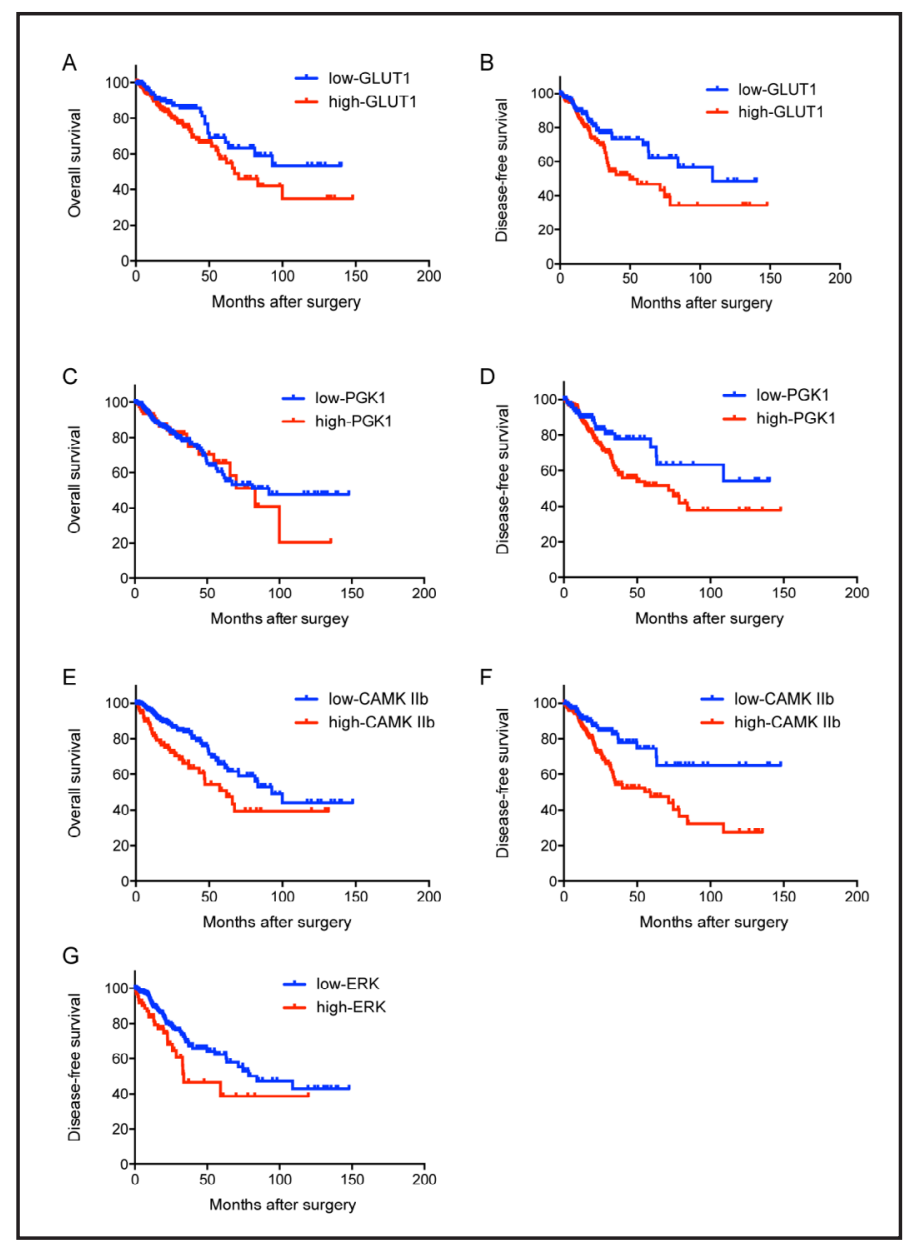

Fig. 6. Overall survival curves showing that higher GLUT1 (A) and CAMKIIb (E) expression is associated with worse survival compared to their lower expression; PGK1 (C) expression with overall survival. Disease-free survival according to the expression status of GLUT1 (B), PGK1 (D), CAMKIIb (F), and ERK (G). were also elevated in the cotreatment group compared with the propofol-treatment alone group (Fig. 3B and 3C).

\section{NMDAR-CAMKII-ERK-HIF1 $\alpha$ signaling in propofol-induced glycolysis inhibition}

The influx of extracellular $\mathrm{Ca}^{2+}$ through NMDAR is required for cell signal transduction. To determine how these signaling events contribute to the maintenance of glycolytic metabolism in HT29 and SW480 cells, we studied the effect of MK801, KN93, and rapastinel on intracellular $\mathrm{Ca}^{2+}$ levels and the levels of p-CAMKII and p-ERK. Flow cytometry analysis demonstrated that MK801 significantly reduced intracellular $\mathrm{Ca}^{2+}$ levels, as propofol did, while rapastinel attenuated the inhibitory effect of propofol (Fig. 4A). KN93 showed no effect on intracellular $\mathrm{Ca}^{2+}$ levels (Fig. 4A). Next, immunoblots showed that, consistent with propofol, MK801 and KN93 repressed the levels of p-CAMKII, p-ERK, and HIF1 $\alpha$, while rapastinel reversed the effect of propofol (Fig. 4B).

\section{Propofol inhibits aerobic glycolysis and tumor growth in vivo}

Having established an important role for propofol in glycolysis in vitro, we next examined its effect in vivo. To establish a xenograft model, we first administered propofol, MK801, KN93, rapastinel+propofol, or DMEM to murine CT26 colon cells, consistent with the in vitro 


\section{Cellular Physiology Cell Physiol Biochem 2018;46:492-504 \\ \begin{tabular}{c|c} 
DOI: 10.1159/000488617 & $\begin{array}{l}\text { O } 2018 \text { The Author(s). Published by S. Karger AG, Basel } \\
\text { wwww.karger.com/cpb }\end{array}$
\end{tabular} \\ Chen et al.: Propofol Disrupts Aerobic Glycolysis in Colorectal Cancer Cells}

treatments. Twenty-five female BALB/c mice were randomly divided into 5 groups. Then, the 5 groups of differently treated CT26 cells were injected subcutaneously into the right flanks of the 5 randomly divided groups. Compared with the control group, tumor volume and tumor growth were reduced significantly in the propofol, MK801, and KN93 groups, while tumor growth was increased in the rapastinel+propofol group compared with the propofol group (Fig. 5A). We further determined glucose metabolism in tumor-bearing mice using a small animal imaging system (Fig. 5B). Fig. 5C shows that, compared with the control group, ${ }^{18} \mathrm{~F}-\mathrm{FDG}$ uptake was significantly decreased in the propofol, MK801, and KN93 groups, while rapastinel reversed the inhibition of ${ }^{18} \mathrm{~F}-\mathrm{FDG}$ uptake by propofol. Subsequent qRT-PCR and immunoblot analyses of tumor tissues demonstrated that, compared with the control group, the mRNA and protein expression levels of the glycolytic enzymes GLUT1, HK2, PGK1, and LDHA were also decreased in tissues from the propofol, MK801, and KN93 groups, while they were increased in the rapastinel+propofol group, compared with propofol group (Fig. $5 \mathrm{D}$ and $5 \mathrm{E})$.

High expression of genes involved in glycolysis is correlated with the poor prognosis of colorectal cancer patients after surgery

To detect the potential clinical meaning of genes involved in glycolysis, we obtained 381 colorectal patients from TCGA and classified these patients into low or high gene expression using median expression calculated by Cox regression analysis. Consistent with our findings in vivo and in vitro, Kaplan-Meier analysis showed that the high expression of GLUT1 and CAMKIIb was significantly correlated with a poorer prognosis in colorectal patients (Fig. 6A and 6E). High PGK1 expression was also correlated with a poorer prognosis, but it did not reach the level of significance (Fig. 6C). Patients with high expression of GLUT1, PGK1, CAMKIIb, and ERK had significantly lower disease-free survival than those with low expression (Fig. 6B, 6D, 6F, and 6G). Taken together, these results suggested that the high expression of genes involved in glycolysis has a positive correlation with a poorer prognosis in colorectal patients. Propofol was suggested to inhibit the expression of genes involved in glycolysis in our previous experiments; thus, there is a high possibility that propofol might be beneficial for the treatment of patients with colorectal cancer.

\section{Discussion}

In the present study, we provided evidence that propofol is involved in glucose metabolism in colorectal cancer cells, and the administration of propofol resulted in a reduced capacity for aerobic glycolysis. Moreover, Q-PCR and western blot analysis indicated that propofol inhibited the expression of the main enzymes in glycolysis, such as GLUT1, HK2, PGK1, and LDHA, at both the mRNA and protein levels. Then, we confirmed these results in an in vivo xenograft model. Using a microPET/CT imaging system, we observed that glucose metabolism was reduced in the propofol group, with decreased uptake of ${ }^{18} \mathrm{~F}$-FDG. To elucidate further the specific inhibitory role of propofol on cancer cells, we examined its effect on NCM460, a normal human colon mucosal epithelial cell line, and HUVECs. We found that propofol had little inhibitory effect on the glucose metabolism of normal cells. Previous studies showed that propofol deceases the metastasis and progression of many cancers, including pancreatic cancer [26], breast cancer [27], colon cancer [28], gastric cancer [22], and cervical cancer [29]. However, the specific role of propofol in glucose metabolism in cancer cells remains poorly understood. Here, in the present study, we demonstrated that propofol has an inhibitory role in aerobic glycolysis.

It is well established that hypoxia exists in many tumors, especially solid tumors, for rapidly proliferating cancer cells. Metabolic changes in tumor cells in response to hypoxia enhance glycolytic capacity and decrease mitochondrial respiration. HIF1 $\alpha$ activation is one of the principal mechanisms driving glycolysis in tumor cells, by directly or indirectly targeting the glucose transporters and enzymes involved in glycolysis. As reported previously, propofol can inhibit the activity of HIF $1 \alpha$ and thus attenuate the invasive ability of HIF $1 \alpha$-promoting 


\section{Cellular Physiology Cell Physiol Biochem 2018;46:492-504 \begin{tabular}{l|l|l}
\hline and Biochemistry 10.1159/000488617 & $\begin{array}{l}\text { (c) } 2018 \text { The Author(s). Published by S. Karger AG, Basel } \\
\text { www.karger.com/cpb }\end{array}$
\end{tabular} \\ Chen et al.: Propofol Disrupts Aerobic Glycolysis in Colorectal Cancer Cells}

malignancies [30]. Our data also confirmed that propofol reduced HIF1 $\alpha$ expression in HT29 and SW480 colorectal cancer cells in a dose-dependent manner. A number of studies have demonstrated that HIF1 $\alpha$ expression is regulated by major signaling pathways, including the ERK pathways [25]; therefore, we examined the effect of propofol on ERK activity. As expected, propofol significantly repressed the phosphorylation of ERK. The $\mathrm{Ca}^{2+}$ signaling pathway is also reportedly involved in tumorigenesis. Alterations of $\mathrm{Ca}^{2+}$ levels in cancer cells help to sustain the hallmarks of cancer by remodeling the proliferation, metastasis, and vascularization of tumor cells [31]. As a direct effector of $\mathrm{Ca}^{2+}$ signaling, CAMKII in turn regulates the activation of ERK pathways to facilitate tumor progression [31,32]. Consistent with previous studies, we demonstrated that propofol reduced $\mathrm{Ca}^{2+}$ levels in cancer cells and reduced the levels of p-CAMKII and p-ERK.

There is accumulating evidence suggesting that surgical stress, volatile anesthetics, and blood transfusion may facilitate tumor growth. Moreover, investigations on intravenous anesthetics have discovered that propofol has an opposite effect to inhaled anesthetics, i.e., suppressing metastasis and promoting apoptosis of tumor cells [30, 33-35]. A recent study found that propofol inhibited the activation of NMDAR, a $\mathrm{Ca}^{2+}$ channel [36]. NMDAR, with high permeability to $\mathrm{Ca}^{2+}$, plays a crucial role in synaptic transmission and synaptic plasticity in the nervous system $[37,38]$. A growing body of evidence indicates that NMDAR is also expressed in a wide range of non-neuronal cells, including cancer cells $[39,40]$. To determine whether propofol decreased the levels of cellular $\mathrm{Ca}^{2+}$ through NMDAR inactivation, we used MK801, an antagonist of NMDAR. Our data showed that MK801 mimicked the inhibitory effect of propofol. KN93, an antagonist of CAMKII, also had the same effect as propofol. As a target of $\mathrm{Ca}^{2+}$, CAMKII inhibition through KN93 had no effect on intracellular $\mathrm{Ca}^{2+}$ levels. To investigate further the role of propofol on NMDAR, we used rapastinel, an agonist of NMDAR. As expected, rapastinel reversed the inhibitory effect of propofol on glycolytic metabolism. To examine further the clinical correlation of glycolysis, we used 381 patients obtained from TCGA, and classified them into low and high gene expression groups. Kaplan-Meier curve analysis indicated that the high expression of genes involved in glycolysis was positively correlated with a poorer prognosis and disease-free survival in colorectal patients. These results suggested a beneficial role for propofol in the treatment of patients with colorectal cancer.

The current study has some limitations that should be discussed. We confirmed that propofol inhibited aerobic glycolysis in HT29 and SW480 colorectal cancer cells through the suppression of the NMDAR-CAMKII-ERK pathway. Though the physiological roles of NMDAR in the central nervous system have been elucidated extensively, its role as a channel in cancer cells is not well understood. In our study, we used an antagonist of NMDAR, MK801, to verify our hypothesis that propofol inhibited the activity of NMDAR, leading to reduced intracellular $\mathrm{Ca}^{2+}$ levels, which is not an ideal approach. In addition, NMDAR contain several subunits, and further studies are needed to investigate the specific subunits that propofol may affect. Propofol is used widely during general anesthesia in surgery. However, in the context of surgery, multiple anesthetics are used. Here, it is difficult to study the mechanisms of propofol when the patients have been exposed to other agents. However, the results of our study may still influence the understanding of anesthetics in some way, although further experiments are needed to understand the co-effect of anesthetics used together.

\section{Conclusion}

Our study revealed that propofol has an inhibitory role in the glycolysis of colorectal cancer cells. Our results suggested that propofol inhibited the expression of glucose transporters and enzymes (GLUT1, HK2, LDHA, and PDK1) that are crucial in glucose metabolism. It further supported the hypothesis that HIF1 $\alpha$, a master transcription factor controlling glucose metabolism, is also reduced by propofol in a dose-dependent manner. In addition, we found that propofol repressed the NMDAR-CAMKII-ERK pathway to inactivate HIF $1 \alpha$ and therefore reduce glycolysis (Fig. 5F). The xenograft model also confirmed the 


\section{Cellular Physiology Cell Physiol Biochem 2018;46:492-504 and Biochemistry Published online: April 03, $2018 \quad$\begin{tabular}{l|l} 
DOI: 10.1159/000488617 2018 The Author(s). Published by S. Karger AG, Basel \\
www.karger.com/cpb
\end{tabular} \\ Chen et al.: Propofol Disrupts Aerobic Glycolysis in Colorectal Cancer Cells}

reduction of glucose metabolism and tumor growth by propofol. Patients derived from TCGA with high expression of genes involved in glycolysis had a lower overall survival and diseasefree survival than those with low gene expression, suggesting a potential role for propofol in the treatment of cancer patients. Therefore, the results of our study may contribute to the use of anesthetics in the clinical setting.

\section{Acknowledgements}

This work was supported by the Shanghai Charity Cancer Center (No. HYXH1407). We thank Yi Qin, Ph.D. (Pancreatic Cancer Institute, Fudan University Shanghai Cancer Center, Shanghai, China) for his assistance with technical aspects of performing the experiments, and Yingjian Zhang (Head of Nuclear Medicine Department, Fudan University Shanghai Cancer Center, Shanghai, China) for his assistance in microPET/CT imaging and analysis.

\section{Disclosure Statement}

No conflict of interests exists.

\section{References}

1 Siegel RL, Miller KD, Jemal A: Cancer statistics, 2016 CA Cancer J Clin 2016;66:7-30.

-2 Chen W, Zheng R, Baade PD, Zhang S, Zeng H, Bray F, Jemal A, Yu XQ He J: Cancer statistics in China, 2015 CA Cancer J Clin 2016;66:115-132.

3 Brenner H, Kloor M, Pox CP: Colorectal cancer. Lancet 2014;383:1490-1502.

4 Ferlay J, Soerjomataram I, Dikshit R, Eser S, Mathers C, Rebelo M, Parkin DM, Forman D, Bray F: Cancer incidence and mortality worldwide: sources, methods and major patterns in GLOBOCAN 2012. Int J Cancer 2015;136:E359-386.

5 Caricato M, Borzomati D, Ausania F, Valeri S, Rosignoli A, Coppola R: Prognostic factors after surgery for locally recurrent rectal cancer: an overview. Eur J Surg Oncol 2006;32:126-132.

-6 Jess T, Lopez A, Andersson M, Beaugerie L, Peyrin-Biroulet L: Thiopurines and risk of colorectal neoplasia in patients with inflammatory bowel disease: a meta-analysis. Clin Gastroenterol Hepatol 2014;12:17931800.e1791.

7 Goday A, Barneto I, Garcia-Almeida JM, Blasco A, Lecube A, Gravalos C, Martinez de Icaya P, de las Penas R, Monereo S, Vazquez L, Palacio JE, Perez-Segura P: Obesity as a risk factor in cancer: A national consensus of the Spanish Society for the Study of Obesity and the Spanish Society of Medical Oncology. Clin Transl Oncol 2015;17:763-771.

8 Wang Y, Duan H, Yang H, Lin J: A pooled analysis of alcohol intake and colorectal cancer. Int J Clin Exp Med 2015;8:6878-6889.

9 De Bruijn KM, Arends LR, Hansen BE, Leeflang S, Ruiter R, van Eijck CH: Systematic review and metaanalysis of the association between diabetes mellitus and incidence and mortality in breast and colorectal cancer. Br J Surg 2013;100:1421-1429.

10 Kroemer G, Pouyssegur J: Tumor cell metabolism: cancer's Achilles' heel. Cancer Cell 2008;13:472-482.

$\checkmark 11$ Jang M, Kim SS, Lee J: Cancer cell metabolism: implications for therapeutic targets. Exp Mol Med 2013;45:e45.

12 Denko NC: Hypoxia, HIF1 and glucose metabolism in the solid tumour. Nat Rev Cancer 2008;8:705-713.

13 Guo J, Hao J, Jiang H, Jin J, Wu H, Jin Z, Li Z: Proteasome activator subunit 3 promotes pancreatic cancer growth via c-Myc-glycolysis signaling axis. Cancer Lett 2016;10.1016/j.canlet.2016.08.018

14 Lee SY, Jin CC, Choi JE, Hong MJ, Jung DK, Do SK, Baek SA, Kang HJ, Kang HG, Choi SH, Lee WK, Seok Y, Lee EB, Jeong JY, Shin KM, Cho S, Yoo SS, Lee J, Cha SI, Kim CH, Lee YM, Lee IK, Jheon S, Park JY: Genetic polymorphisms in glycolytic pathway are associated with the prognosis of patients with early stage nonsmall cell lung cancer. Sci Rep 2016;6:35603.

15 Smith B, Schafer XL, Ambeskovic A, Spencer CM, Land H, Munger J: Addiction to Coupling of the Warburg Effect with Glutamine Catabolism in Cancer Cells. Cell Rep 2016;17:821-836.

16 Sprowl-Tanio S, Habowski AN, Pate KT, McQuade MM, Wang K, Edwards RA, Grun F, Lyou Y, Waterman ML: Lactate/pyruvate transporter MCT-1 is a direct Wnt target that confers sensitivity to 3-bromopyruvate in colon cancer. Cancer Metab 2016;4:20. 


\section{Cellular Physiology Cell Physiol Biochem 2018;46:492-504 \begin{tabular}{l|l} 
DOI: 10.1159/000488617 & Ond 2018 The Author(s). Published by S. Karger AG, Basel \\
www.karger.com/cpb
\end{tabular} \\ Chen et al.: Propofol Disrupts Aerobic Glycolysis in Colorectal Cancer Cells}

17 Toyonaga T, Yamaguchi S, Hirata K, Kobayashi K, Manabe O, Watanabe S, Terasaka S, Kobayashi H, Hattori N, Shiga T, Kuge Y, Tanaka S, Ito YM, Tamaki N: Hypoxic glucose metabolism in glioblastoma as a potential prognostic factor. Eur J Nucl Med Mol Imaging 2016;10.1007/s00259-016-3541-z

18 Camara O, Kavallaris A, Noschel H, Rengsberger M, Jorke C, Pachmann K: Seeding of epithelial cells into circulation during surgery for breast cancer: the fate of malignant and benign mobilized cells. World J Surg Oncol 2006;4:67.

19 Ciechanowicz SJ, Ma D: Anaesthesia for oncological surgery - can it really influence cancer recurrence? Anaesthesia 2016;71:127-131.

20 Deng F, Ouyang M, Wang X, Yao X, Chen Y, Tao T, Sun X, Xu L, Tang J, Zhao L: Differential role of intravenous anesthetics in colorectal cancer progression: implications for clinical application. Oncotarget 2016;10.18632/oncotarget.12800

21 Ecimovic P, Murray D, Doran P, Buggy DJ: Propofol and bupivacaine in breast cancer cell function in vitro role of the NET1 gene. Anticancer Res 2014;34:1321-1331.

22 Peng Z, Zhang Y: Propofol inhibits proliferation and accelerates apoptosis of human gastric cancer cells by regulation of microRNA-451 and MMP-2 expression. Genet Mol Res 2016;15:

23 Zhu Y, Qiu P, Ji Y: TCGA-assembler: open-source software for retrieving and processing TCGA data. Nat Methods 2014;11:599-600.

24 Mathy-Hartert M, Deby-Dupont G, Hans P, Deby C, Lamy M: Protective activity of propofol, Diprivan and intralipid against active oxygen species. Mediators Inflamm 1998;7:327-333.

25 Masoud GN, Li W: HIF-1 $\alpha$ pathway: role, regulation and intervention for cancer therapy. Acta Pharm Sin B 2015;5:378-389.

26 Chen X, Wu Q You L, Chen S, Zhu M, Miao C: Propofol attenuates pancreatic cancer malignant potential via inhibition of NMDA receptor. Eur J Pharmacol 2017;795:150-159.

27 Chen X, Lu P, Chen L, Yang SJ, Shen HY, Yu DD, Zhang XH, Zhong SL, Zhao JH, Tang JH: Perioperative propofol-paravertebral anesthesia decreases the metastasis and progression of breast cancer. Tumour Biol 2015;36:8259-8266.

28 Xu YJ, Li SY, Cheng Q Chen WK, Wang SL, Ren Y, Miao CH: Effects of anaesthesia on proliferation, invasion and apoptosis of LoVo colon cancer cells in vitro. Anaesthesia 2016;71:147-154.

29 Zhang D, Zhou XH, Zhang J, Zhou YX, Ying J, Wu GQ Qian JH: Propofol promotes cell apoptosis via inhibiting HOTAIR mediated mTOR pathway in cervical cancer. Biochem Biophys Res Commun 2015;468:561-567.

-30 Huang H, Benzonana LL, Zhao H, Watts HR, Perry NJ, Bevan C, Brown R, Ma D: Prostate cancer cell malignancy via modulation of HIF-1alpha pathway with isoflurane and propofol alone and in combination. Br J Cancer 2014;111:1338-1349.

-31 Prevarskaya N, Ouadid-Ahidouch H, Skryma R, Shuba Y: Remodelling of Ca2+ transport in cancer: how it contributes to cancer hallmarks? Philos Trans R Soc Lond B Biol Sci 2014;369:20130097.

-32 Roderick HL, Cook SJ: Ca2+ signalling checkpoints in cancer: remodelling Ca2+ for cancer cell proliferation and survival. Nat Rev Cancer 2008;8:361-375.

-33 Iwasaki M, Zhao H, Jaffer T, Unwith S, Benzonana L, Lian Q, Sakamoto A, Ma D: Volatile anaesthetics enhance the metastasis related cellular signalling including CXCR2 of ovarian cancer cells. Oncotarget 2016;7:26042-26056.

-34 Liu Z, Zhang J, Hong G, Quan J, Zhang L, Yu M: Propofol inhibits growth and invasion of pancreatic cancer cells through regulation of the miR-21/Slug signaling pathway. Am J Transl Res 2016;8:4120-4133.

35 Wang P, Chen J, Mu LH, Du QH, Niu XH, Zhang MY: Propofol inhibits invasion and enhances paclitaxelinduced apoptosis in ovarian cancer cells through the suppression of the transcription factor slug. Eur Rev Med Pharmacol Sci 2013;17:1722-1729.

-36 Gong HY, Zheng F, Zhang C, Chen XY, Liu JJ, Yue XQ: Propofol protects hippocampal neurons from apoptosis in ischemic brain injury by increasing GLT-1 expression and inhibiting the activation of NMDAR via the JNK/Akt signaling pathway. Int J Mol Med 2016;38:943-950.

37 Bouvier G, Bidoret C, Casado M, Paoletti P: Presynaptic NMDA receptors: Roles and rules. Neuroscience 2015;311:322-340.

-38 Paoletti P: Molecular basis of NMDA receptor functional diversity. Eur J Neurosci 2011;33:1351-1365.

-39 Hogan-Cann AD, Anderson CM: Physiological Roles of Non-Neuronal NMDA Receptors. Trends Pharmacol Sci 2016;37:750-767.

40 Deutsch SI, Tang AH, Burket JA, Benson AD: NMDA receptors on the surface of cancer cells: target for chemotherapy? Biomed Pharmacother 2014;68:493-496. 